\title{
Complications of Temporary Percutaneous Mechanical Circulatory Support for Cardiogenic Shock: An Appraisal of Contemporary Literature
}

\author{
Anna V. Subramaniam · Gregory W. Barsness · Saarwaani Vallabhajosyula • \\ Saraschandra Vallabhajosyula (D)
}

Received: September 17, 2019 / Published online: October 23, 2019

(C) The Author(s) 2019

\begin{abstract}
Cardiogenic shock (CS) is associated with hemodynamic compromise and end-organ hypoperfusion due to a primary cardiac etiology. In addition to vasoactive medications, percutaneous mechanical circulatory support (MCS) devices offer the ability to support the hemodynamics and prevent acute organ failure. Despite the wide array of available MCS devices for CS, there are limited data on the complications from these devices. In this review, we seek to summarize the complications of MCS devices in the contemporary era. Using a systems-based approach, this review covers domains of hematological, neurological, vascular, infectious, mechanical, and miscellaneous complications.
\end{abstract}

Enhanced Digital Features To view enhanced digital features for this article go to https://doi.org/10.6084/ m9.figshare.9945059.

A. V. Subramaniam

Department of Medicine, Mayo Clinic, Rochester, MN, USA

G. W. Barsness · S. Vallabhajosyula

S. Vallabhajosyula $(\bowtie)$

Department of Cardiovascular Medicine, Mayo

Clinic, Rochester, MN, USA

e-mail: vallabhajosyula.saraschandra@mayo.edu

S. Vallabhajosyula

Division of Pulmonary and Critical Care Medicine,

Department of Medicine, Mayo Clinic, Rochester,

MN, USA
These data are intended to provide a balanced narrative and aid in risk-benefit decision-making in this acutely ill population.

Keywords: Cardiogenic shock; Complications; Impella; Intra-aortic balloon pump; Mechanical circulatory support; TandemHeart; Venoarterial extracorporeal membrane oxygenation

\section{Key Summary Points}

Many mechanical circulatory support (MCS) devices are available for the management of cardiogenic shock

There are limited data on the complications from MCS device placement in patients with cardiogenic shock

This review summarizes the complications from MCS devices in the contemporary era in a systematic fashion

Major complications include bleeding, vascular/access issues, hemolysis, cerebrovascular accidents, limb ischemia, sepsis and left ventricular distension 


\section{INTRODUCTION}

Cardiogenic shock (CS) is a state of low cardiac output resulting in life-threatening end-organ hypoperfusion and hypoxia [1]. Acute myocardial infarction (AMI) with consequent left ventricular (LV) dysfunction remains the most common etiology and comprises nearly $80 \%$ of all CS [1-5]. Less frequently, CS is seen as a complication of post-cardiotomy status, endstage heart failure, Takotsubo cardiomyopathy, acute pulmonary embolism, acute myocarditis, and septic cardiomyopathy [6-14]. Historically, CS patients were managed with the use of highdose vasopressors/inotropes and the use of intra-aortic balloon pump (IABP) for mechanical circulatory support (MCS) [15]. The use of vasopressors and inotropes for the management of AMI-CS is associated with adverse hemodynamic effects and high myocardial oxygenation consumption, which may be associated with worsening shock [6, 16-18]. Newer percutaneous MCS, such the transvalvular axial flow pumps (Impella ${ }^{\circledR}$ ), TandemHeart ${ }^{\circledR}$ and veno-arterial extracorporeal membrane oxygenation (VA-ECMO) have resulted in a paradigm shift in the management of these patients [19]. The current MCS devices improve hemodynamics and decrease the requirement for vasoactive medications [1]. In current practice, advanced percutaneous MCS devices offer attractive alternatives to IABP [19]. The physiologic rationale for MCS includes a decrease in myocardial oxygen demand, LV unloading resulting in decreased LV wall stress, facilitation of myocardial recovery by increasing microvascular flow, and weaning from toxic vasoactive medications that might result in higher myocardial oxygen consumption and worsen refractory shock [16, 20-24].

However, these newer MCS devices are associated with a higher risk of complications, which are variably reported in the literature $[19,21,25-28]$. This variability can be attributed to many factors including changes in technology and insertion techniques of devices over time, differences in patient baseline characteristics and clinical setting, and variability in operator experience based on single-center versus multicenter trials. Additionally, time to follow-up is often only until hospital discharge, but some complications are reported more frequently with longer follow-up periods $[29,30]$. The various configurations, extent of support, and access for these devices have been described previously and will not be discussed in this review $[1,19,31,32]$. The aim of this review is to assess the reported complications and complication rates reported in the literature with four common forms of temporary MCS, and to discuss risk factors that have been identified for the development of complications (Fig. 1 and Table 1).

\section{COMPLICATIONS OF TEMPORARY PERCUTANEOUS MECHANICAL CIRCULATORY SUPPORT}

\section{Hematological Complications}

\section{Major Bleeding}

Major bleeding rates are defined and reported differently across studies [21, 33-40]. For the purpose of this review, major bleeding is defined as the need for blood transfusion, or reported bleeding complication that was not defined as an access-site related bleed [33, 37, 38, 41-45]. The use of percutaneous MCS necessitates continuous anticoagulation, which often results in concomitant bleeding. Bleeding rates are affected by the activated clotting time (ACT) recommended for different devices and degree of thrombocytopenia, which is often seen due to the mechanical shear strain of these devices [19]. Early studies of percutaneous IABP insertions prior to 2000 reported bleeding rates ranging from 5 to $8 \%$ [46-49]. In a recent systematic review of complications from the IABP, de Jong et al. noted an incidence of bleeding between 0.4 and $27.7 \%$ [50]. In a comparative study of all randomized trials comparing percutaneous MCS (Impella or TandemHeart) to the IABP, Thiele et al. reported $17 \%$ bleeding rates for IABP support in AMI-CS [51]. One trial investigating IABP in combination with different thrombolytic regimens for AMI reported a moderate bleeding rate of $47 \%$ 


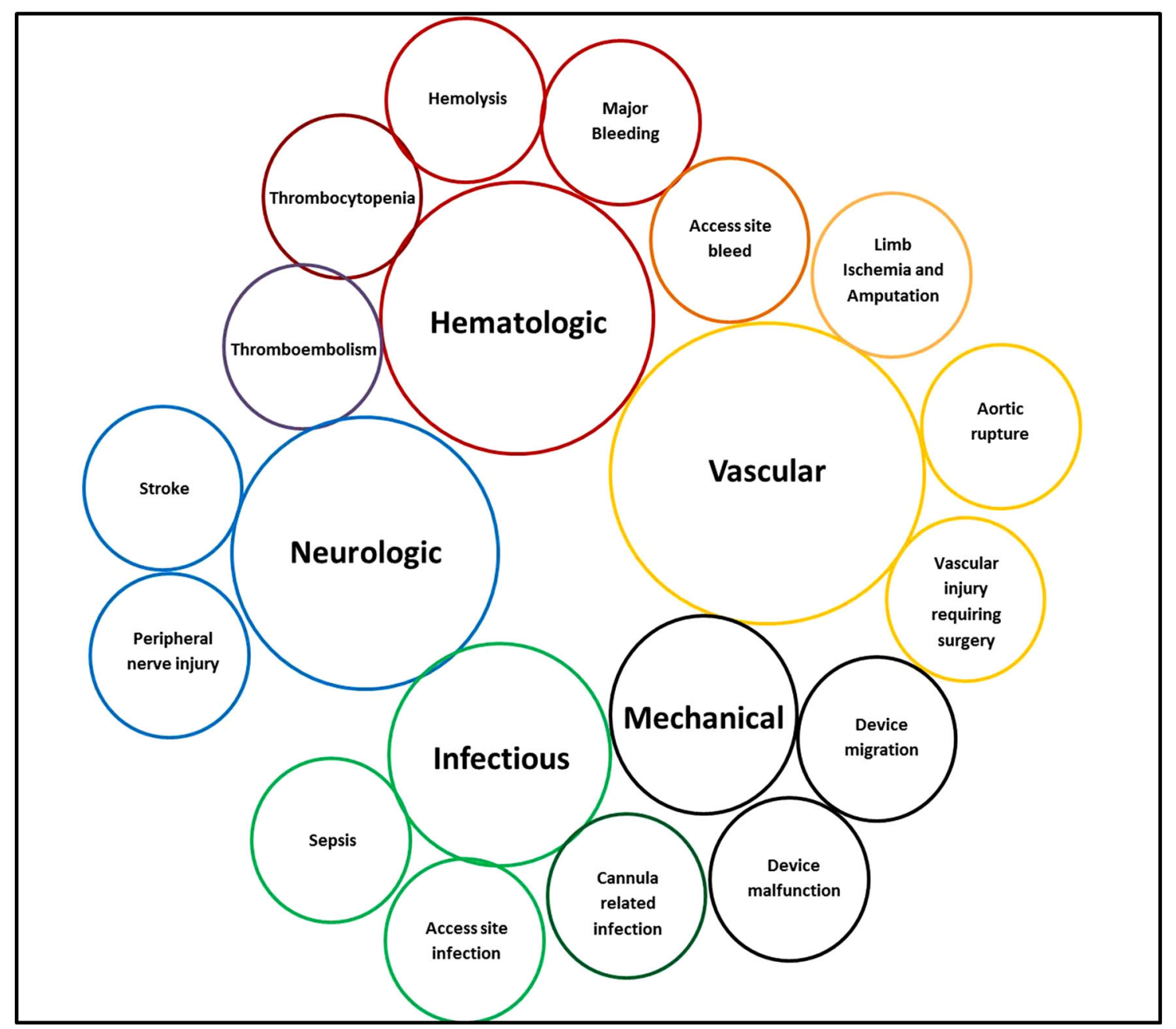

Fig. 1 Complications of MCS by category. Each color represents a unique complication category. Complications across more than one category are shown in a combination of colors of the two categories

and severe bleeding rate of $10 \%$ [52]. Studies of IABP to support PCI report bleeding rates of 3.3-8.4\% [53-55]. More recent studies of IABP for $\mathrm{AMI}, \mathrm{CS}, \mathrm{UA}$, and perioperative use report rates from 0.8 to $26.3 \%$ [33-35, 37, 39, 41, 56-60]. Bleeding rates for Impella ${ }^{\circledR}$ are poorly described, but range from as low as $0.05 \%$ to $54 \%$ when inserted percutaneously [21, 44, 61-64]. In a meta-analysis of randomized trials in AMI-CS, compared to the IABP, the Impella had a 2.5-fold higher risk of major bleeding [51]. TandemHeart bleeding rates are significantly higher, from 53 to $59.8 \%$ $[65,66]$. This may be linked to the need for trans-septal puncture, as well as higher index of comorbidity in patients receiving TandemHeart. Rates of major bleeding in VA-ECMO have the most variability, ranging from 5 to $81 \%$ [67]. In a meta-analysis of nearly 1900 patients receiving VA-ECMO, Cheng et al. noted major bleeding in $41 \%$ (95\% confidence interval $27-57 \%$ ) and the need for re-thoracotomy for major bleeding or tamponade in $42 \%$ of all recipients [25].

The mechanisms for bleeding include blood loss in the device circuit, need for anticoagulation, access-site issues, hemolysis due to mechanical strain, thrombocytopenia, acquired von Willebrand syndrome and high shear stress on the circulating blood [25, 67]. Typical sites 
Table 1 Prevalence of complications in patients receiving temporary mechanical circulatory support

\begin{tabular}{|c|c|c|c|c|}
\hline Complication & IABP & Impella & TandemHeart & ECMO \\
\hline \multicolumn{5}{|l|}{ Hematologic } \\
\hline Major bleeding & $0.8-47$ & $0.05-54$ & $53-59$ & $5-81$ \\
\hline Access site bleeding & $2-27$ & $2-40$ & $8-53$ & 6 \\
\hline Hemolysis & $0.7-7.2$ & $10-46$ & 5.3 & $9.2-18$ \\
\hline Thrombocytopenia & 43 & - & - & $8.3(\mathrm{HIT})$ \\
\hline \multicolumn{5}{|l|}{ Neurologic } \\
\hline Cerebrovascular accident & $1-7$ & $2.4-6.3$ & & $1.6-17.6$ \\
\hline Neuropathy & $0.4-24$ & - & - & - \\
\hline \multicolumn{5}{|l|}{ Vascular } \\
\hline Limb ischemia & $0.3-42$ & $0.07-10$ & $3.4-11$ & $4.3-50$ \\
\hline Amputation & $0.1-1$ & - & - & $0-1.1$ \\
\hline Thromboembolism & $1.1-8.6$ & - & - & 18 \\
\hline Aortic rupture/dissection & $0.09-9$ & - & - & $<1$ \\
\hline Vascular injury requiring surgery & $0.01-13.3$ & $1.3-2$ & $0.85-13$ & 4.7 \\
\hline \multicolumn{5}{|l|}{ Infectious } \\
\hline Access site infection & $0.5-35$ & 1.1 & 16 & $1.1-17.7$ \\
\hline Sepsis & $1-15.7$ & $0.16-19$ & 29.9 & $12.9-31$ \\
\hline \multicolumn{5}{|l|}{ Mechanical } \\
\hline Device migration & $1-8$ & $0.05-23$ & 8 & - \\
\hline Device malfunction & $0.9-8.3$ & $0.16-17$ & - & $16.8-29$ \\
\hline
\end{tabular}

All values are expressed as percentage

ECMO extracorporeal membrane oxygenation, $L A B P$ intra-aortic balloon pump

for hemorrhage (beside access site) include the pulmonary and neurological systems [68, 69]. In about $5 \%$ of the population, significant gastrointestinal hemorrhage is noted in patients with pre-existing risk factors [64]. Neurological hemorrhage is often associated with catastrophic outcomes resulting in cessation of MCS use and/or withdrawal of life support [68, 69]. In patients with cardiac or respiratory pathology, such as cardiac arrest, acute respiratory distress syndrome, cardiogenic shock, and postcardiotomy status, it is difficult to ascribe these bleeding complications to the mechanisms associated with use of MCS alone. It is possible that these patients have a higher risk of complications regardless of the type of MCS device used.

\section{Access Site Hematoma or Bleeding}

Due to the use of large-bore peripheral arterial and/or venous access, the use of advanced percutaneous MCS is often associated with access site complications [31, 43, 51]. The rates of access side-related complications vary widely by sheath size and by closure technique, which is device- and patient-dependent. Despite the use of 'safe-femoral' access in contemporary catheterization laboratories in the 
contemporary era, the need for emergent access under suboptimal situations often results in higher rates of complications in these patients [70]. There appears to be a direct relationship to size of the vascular cannulae used in these patients. Furthermore, there have been recent reports of the use of more than one type of MCS concomitantly in these patients to offset the limitations of one MCS device with the other and provide incremental cardiac output support [7-10, 71]. Conceivably, this strategy may be associated with higher rates of complications and therefore needs to be carefully balanced against the realistic need for dual mechanical circulatory support $[7,8]$.

The IABP is complicated by access-site bleeding in $2-27 \%$ of insertions, but rates have been consistently below $10 \%$ in recent years [33, 35, 41, 47, 49, 53, 54, 59, 72-75]. Access-site complication is infrequently reported for Impella ${ }^{\circledR}$ 2.5. The PROTECT I Trial, a multicenter safety and feasibility study of the Impella ${ }^{\circledR} 2.5$ in 20 patients undergoing highrisk PCI, has the highest reported rate at $40 \%$ [44]. This may be related to the small sample size and limited operator familiarity with the device. The PROTECT II trial of 448 patients with Impella ${ }^{\circledR}$ insertion did not report accesssite complications [29]. More recent series have identified lower rates around 2\%; however insertion techniques included both surgical and percutaneous approaches [76]. TandemHeart ${ }^{\circledR}$ has the highest risk of access-site-related complications, which is likely related to the large sheath required for insertion. Rates range from 8 to $53 \%[38,65,66,77]$. The highest reported rate of $53 \%$ is from a small retrospective study with only 19 TandemHeart $^{\circledR}$ insertions [77]. Access-site bleeding is also very infrequently reported in the VA-ECMO literature, with a reported rate of $6 \%$ in a retrospective study of 184 insertions [40]. Lastly, there are limited comparative reports of access site bleeding related to different configurations of MCS devices such as Impella CP versus 5.0, peripheral versus central VA-ECMO, and femoral versus axillary IABP [78].

\section{Hemolysis}

The mechanism of hemolysis in patients with temporary MCS is by shear stress from axial pumping. Hemolysis is an infrequently reported complication across all forms of MCS due to challenges in determining true hemolysis. Hemolysis can be measured directly by plasmafree hemoglobin, which is more accurate $[44,79,80]$, or indirectly by traditional methods of laboratory evaluation. Given the frequent need for blood transfusion in patients with temporary MCS without a clearly identified source of blood loss in many cases, the true rate of hemolysis may be higher than reported.

One small prospective multi-center study compared IABP and TandemHeart ${ }^{\circledR}$ for the treatment of cardiogenic shock and investigated plasma-free hemoglobin in seven IABP patients and nine TandemHeart ${ }^{\circledR}$ patients [80]. Rates of hemolysis were $7.2 \%$ and $5.3 \%$ respectively [80]. A larger retrospective single-center study of 3135 IABP insertions from 1985 to 2013 found a much lower rate of $0.7 \%$ [75]. In patients requiring Impella support, prior works from large registries have demonstrated hemolysis rates of $7-8 \%[81,82]$. In a retrospective study of 112 CS patients, Badiye et al. demonstrated a cumulative incidence of hemolysis of nearly $63 \%$ [83]. Longer duration of Impella support was associated with a continued need for blood transfusion suggestive of ongoing hemolysis [83]. Furthermore, further data are needed due to define the optimal cut-offs of laboratory parameters in patients with CS being evaluated for hemolysis due to baseline elevations in lactate dehydrogenase [84]. The differences in clinical cut-offs might explain the wide variations in the reported rates of hemolysis with the Impella device [82-84]. Hemolysis is more prevalent in VA-ECMO secondary to the inherent design of the ECMO filter and circuit that is associated with shear forces due to centrifugal pumps and high resistance flow through the oxygenator [85]. A meta-analysis of complications and mortality of ECMO including studies from 1998 to 2011 reported hemolysis rate of $18 \%$ [86], but a more recent retrospective study of ECMO cannulations at a single center from 2014 to 2018 reports a lower rate of $9.2 \%$ [40]. These data are consistent with data from the 
Extracorporeal Life Support Organization data that demonstrated hemolysis in $10 \%$ and $7 \%$ of pediatric and adult patients, respectively [87]. This may be attributed to better patient selection, improved anticoagulation protocols, and improvement in ECMO circuits [85].

\section{Thrombocytopenia}

Thrombocytopenia is classified by severity (mild, moderate, or severe), but for this review will be defined as platelet count $<150,000 / \mathrm{ml}$ or $>50 \%$ decrease from baseline [37]. In patients with MCS, thrombocytopenia needs careful evaluation since it might be induced by heparin as against being a device-related complication. In 252 patients receiving the IABP (Roy et al.), 43\% of patients developed thrombocytopenia [37]. Interestingly, thrombocytopenia did not lead to a significant increase in bleeding or change in outcomes. They also found that heparin-induced thrombocytopenia (HIT) occurred in only a small number of patients and did not significantly affect the rate of thrombocytopenia. There are limited data on thrombocytopenia with the Impella ${ }^{\circledR}$ and the TandemHeart ${ }^{\circledR}$ [88]. Rates are not reported in the ECMO literature, but it is of note that HIT is an important entity in this patient population $[89,90]$. In a retrospective single-center analysis of 118 ECMO cannulations from 2009 to 2013, $74 \%$ of patients had a HIT ELISA or serotonin release assay performed within 14 days of initiating ECMO [89]. Of the $74 \%$ who were screened, $8.3 \%$ were determined to have HIT and documentation of concurrent thromboembolic events while on ECMO [89]. The authors investigated platelet count trend and time to platelet count nadir and found that the overall platelet count trend was not significantly different in patients with or without HIT, as almost all patients have a significant degree of ECMO-induced thrombocytopenia [89]. They did find that time to platelet nadir was significantly longer in the HIT-positive group, but attributed this to the longer average time on ECMO observed in this group [89]. Based on these observations, previously validated prediction scores like the $4 \mathrm{~T}$ score are not useful in this population and it is consensus to test and treat for HIT based on high clinical suspicion $[89,90]$.

\section{Neurological Complications}

\section{Cerebrovascular Accidents}

Cerebrovascular accidents (CVA) are a common complication, and are frequently reported as a composite of all cerebrovascular accidents including ischemic CVA, hemorrhagic CVA, and transient ischemic attacks. In patients with $\mathrm{CS}$, there is often concomitant neurological injury due to hypoperfusion, hypoxemia, hyperglycemia, or pyrexia $[3,68]$. Furthermore, patients with CS often have overlapping cardiac arrest that is associated with low-flow state and ischemic-reperfusion neurological injury [3]. Therefore, the assessment of neurological injury and development of CVA is complex in this population. CVA rate in IABP is typically low, $1-10 \%$

$[35,39,42,49,52,53,55,56,58,74,75,91]$. Impella ${ }^{\circledR}$ and TandemHeart ${ }^{\circledR}$ have rates similar to IABP, reported from 2.4 to $6.3 \%$ $[29,65,66,82,88]$. Rates of CVA are significantly higher in ECMO, ranging from 3.3 to $17.6 \%$ for ischemic CVA $[40,69,86,92-96]$ and $1.6-5 \%$ for hemorrhagic CVA [40, 68, 95-97]. Use of anticoagulation in these patients places them at a higher risk of hemorrhagic CVA or hemorrhagic transformation of ischemic CVA [98].

\section{Neuropathy}

Neuropathy has been described primarily as a complication downstream of lower-limb ischemia in patients with IABP. There have been isolated reports of femoral cutaneous neuropathy occurring in patients without limb ischemia [99]. Rates of persistent paresthesia and foot drop are reported from 0.4 to $4 \%$ $[47,48,100,101]$, with one study from 1987 citing a rate of $24 \%$ [102]. While this likely occurs with other forms of MCS, incidence is likely not reported due to lack of clinical significance. 


\section{Vascular Complications}

\section{Limb Ischemia}

Limb ischemia is one of the most feared and most common complications across all forms of MCS, and is the most commonly reported given its clinical significance [51, 58, 82, 103]. Limb ischemia is defined as loss of pulses, Doppler signal [104] or arterial thrombus requiring thrombectomy or surgical intervention $[35,41,105]$. The mechanism of limb ischemia is most often arterial thrombus or occlusion of blood flow to the distal extremity by the MCS device [44, 50, 73, 106-108]. In many studies, the incidence of limb ischemia may or may not include patients who ultimately required amputation; however the reported rates of amputation are low [33, 35, 42, 92, 105].

The rate of limb ischemia for IABP insertion demonstrates wide variations in the literature: 0.03 to $42 \%[33-35,42,46,48,55,57,58$, 73, 80, 91, 99, 100, 102, 109-111], however, more recent studies show lower rates of $0.9-12 \%[30,39,41,75]$. This can partly be attributed to improvements in sheath size, better patient selection, and shorter durations of support. Ozen et al. noted lower rates of limb ischemia $(9.2 \%$ vs. $14.1 \%)$ in patients receiving the IABP without a insertion sheath [75]. In the contemporary cohort of four randomized trials evaluating IABP and Impella in CS, Thiele et al. demonstrated significantly lower rates of limb ischemia with the former (3\% vs. 17\%) [51]. In 112 AMI-CS patients receiving Impella support, limb ischemia was noted in 3\% of the patients over 12 years at a high-volume Danish center [82]. Comparing Impella $\mathrm{CP} / 5.0$ to the VA ECMO in 128 patients, Karami et al. noted the Impella group to have lower rates of limb ischemia (2\%) compared to the VA ECMO (5\%) [64]. There are fewer data on the TandemHeart, with reported ranges of $3.4-11 \%[65,66]$. There is wide variability on the contemporary rates of the ischemia in patients receiving VA ECMO [40, 86, 92-95, 107, 108]. This is significantly influenced by the urgency of the cannulation, disease processing needing VA ECMO support, cannulation techniques, definition of limb ischemia, caliber of the femoral blood vessels, and the use of distal perfusion cannula
$[112,113]$. In patients with VA-ECMO, IABP are Impella that may be used to unload the LV to achieve myocardial recovery and decreased LV stasis $[7,8]$. In such patients, the use of bilateral femoral access is associated with a higher risk of limb ischemia [113]. Careful serial monitoring of distal perfusion and a potential role for distal perfusion cannula in the ipsilateral extremity are pertinent considerations.

\section{Amputation}

Amputation is a rare but serious complication of MCS caused by prolonged limb ischemia. Rates are most frequently reported in IABP and range from 0.1 to $1 \%$ [33-35, 48, 73, 100]. Rates of amputation with VA-ECMO are $0.7-2.8 \%$ $[94,105,106,114-117]$. There is one isolated case series of 14 VA-ECMO cannulations in which one patient required amputation for limb ischemia, however this is an outlier based on a small sample size [92]. There are no documented amputations with Impella ${ }^{\circledR}$ or TandemHeart ${ }^{\circledR}$.

\section{Other Thrombotic Complications}

Thromboembolic events causing complications other than limb ischemia are also common. These include thromboembolism not otherwise specified, pulmonary embolism, and mesenteric ischemia. Pulmonary embolism is reported with fairly low rates of $0.1-0.5 \%$ in IABP $[35,109]$. Mesenteric ischemia has been identified in three IABP studies with rates of $0.1 \%$ [35], 0.5\% [109], and 1.9\% [91]. Rates of other thromboembolic events range from 1.1 to $8.6 \%$ $[35,39,47,57,80,91,109]$. There is also a single case report involving spinal cord infarction [118].

\section{Vascular Injury Requiring Surgery (Non-Access Site)}

Vascular injury requiring surgery is typically access site-related, but these complications are occasionally grouped with aortic injury. Reported rates of vascular injury in IABP insertion range from 0.01 to $5.3 \%$ $[35,39,55,57,74,110,119]$, with two studies citing $12-13 \%$ [91, 120]. Rates with TandemHeart $^{\circledR}$ range from 0.85 to $13 \%[38,45,88]$. 
A recent study cited vascular complications of ECMO at $4.7 \%$ [3].

\section{Aortic Rupture or Dissection}

Rates of rupture and dissection are most commonly reported with older studies of IABP, ranging from 0.09 to $4 \%$ $[42,47,75,91,109,110]$. One study cited a rate of $9 \%$ based on postmortem examination, suggesting this may be more common [73]. Aortic rupture from ECMO is only documented in one study, with a rate $<1 \%$ [36].

\section{Infectious Complications}

\section{Access Site Infection}

Access site infection is most commonly reported in IABP, with rates ranging from 0.5 to $35 \%$ $[47,48,101,109,110]$. This may represent an underestimate, as many studies group all access site-related complications together, which includes bleeding, infection, and vascular injury. TandemHeart ${ }^{\circledR}$ rate is reported in one single-center study of 54 patients at 16\% [38]. ECMO is also only reported in one study at 1.1\% [40]. Cannula-related infection (CRI) in VAECMO has been well described with rates ranging from 3.5 to $17.7 \%$ [121]. Given the high incidence of CRI, many centers utilize prophylactic antibiotics to reduce the risk of both CRI and other nosocomial infections, however this is not standardized [122]. O'Horo, et al. performed a systematic review investigating the effects of prophylactic antibiotics to reduce the risk of nosocomial infection. They found that patients with open chest wounds and other high-risk conditions like neutropenia benefited from antibiotic prophylaxis, but there was no evidence to support antibiotic prophylaxis beyond standard surgical prophylaxis in ECMO patients who have no other indication for prophylaxis [122]. This recommendation is consistent with the Extracorporeal Life Support Organization (ELSO) Guidelines [123].

\section{Sepsis and Bacteremia}

Sepsis and bacteremia cannot always be ascribed exclusively to MCS, as patients requiring MCS are critically ill and typically have a multitude of potential sources of infection including mechanical ventilation, venous and arterial catheterization, urinary catheterization, and additional surgical intervention [122]. The overall rates of sepsis and bacteremia are similar across all types of temporary MCS with IABP at $1-15.7 \%$

$[39,47,49,55,58,74,75,91,109,110]$, TandemHeart ${ }^{\circledR} 29.9 \%$ [38], and ECMO $12.9-31 \%$ [40, 92-94, 121].

In patients admitted with sepsis, septic cardiomyopathy is seen increasingly in contemporary practice $[6,11,17,124-132]$. These patients typically have superimposed CS due to septic cardiomyopathy in addition to vasoplegic shock from sepsis. Such patients may benefit from the use of institution of VA-ECMO in addition to pharmacological support [133, 134]. Lastly, patients with sepsis often have frequent acute respiratory distress syndrome that might necessitate veno-venous ECMO support for poor respiratory mechanics [135-137]. Therefore, the relationship between sepsis and MCS is bidirectional and the pathophysiological course needs careful definition to understand causal relationships.

\section{Mechanical Complications}

\section{Device Migration}

Device migration is infrequently reported. Rates for IABP insertion range from 1 to $8 \%$ when monitored by serial chest X-ray [33, 111]. Migration is only reported in the initial safety studies of Impella ${ }^{\circledR}$ at $0.05 \%$ [79], and in only one TandemHeart ${ }^{\circledR}$ study at 8\% [38]. Device migration is not reported for ECMO.

\section{Device Malfunction}

Device malfunction varies by type of MCS. IABP malfunction is typically defined by balloon rupture with rates ranging from 0.9 to $8.3 \%$ $[34,35,39,42,46,47,75,91]$. Malfunction is only reported in two Impella ${ }^{\circledR}$ studies at $0.16 \%$ [79] in the initial safety studies and $17 \%$ in a more recent retrospective study comprising both medical and surgical insertions [76]. Malfunction is not reported with TandemHeart ${ }^{\circledR}$. VA-ECMO has a relatively high rate of device 
malfunction, which has increased in recent years likely secondary to increased application. Malfunction of ECMO is often related to oxygenator dysfunction. Two recent studies cite malfunction rates of $16.8 \%$ [40] and 29\% [86].

\section{Other Complications}

\section{Atrial Perforation}

Atrial perforation is a complication unique to TandemHeart ${ }^{\circledR}$, secondary to the need for transseptal puncture, and has been reported with relatively low rates of $0.85 \%$ in initial studies [65].

\section{Left Ventricular Distension}

$\mathrm{LV}$ distension (LVD) is a complication unique to ECMO. LVD is caused by an already-weakened ventricle pumping against an increased blood flow created by VA-ECMO [138]. It has been well described by Truby et al., with rates of subclinical LVD up to $22 \%$ and clinical LVD of $7 \%$ [139]. Subclinical LVD was defined as radiographic evidence of pulmonary edema and pulmonary artery diastolic pressure greater than $25 \mathrm{mmHg}$, while clinical LVD required immediate decompression. LVD has been addressed in many studies by attempting concurrent IABP and Impella ${ }^{\circledR}$ as a mechanism of offload the left ventricle with overall improvement in outcomes [16, 96, 140-148]. Meani et al. reviewed combinations of mechanical circulatory support and found that the most common locations for unloading were the left atrium, the aorta via IABP and trans-aortic [148]. More recent systematic reviews have determined that LV unloading via combinations of MCS can be associated with increased hemolysis, but has no increase in incidence of other major complications. Furthermore, LV unloading has been associated with decreased mortality, indicating a need for randomized trials to determine the best strategy for unloading [138].

\section{RISK FACTORS FOR COMPLICATIONS}

Many studies have investigated risk factors that predispose patients to complications of temporary MCS insertion, primarily in IABP. Factors identified include older age, female sex, body surface area $(\mathrm{BSA})<1.8 \mathrm{~m}$ [2], peripheral vascular disease, smoking history, diabetes, and hypertension [42, 47, 91, 120, 149]. A singlecenter study of 206 consecutive IABP insertion attempts for CS, unstable angina and cardiac arrest noted female sex and peripheral vascular disease to be significant predictors of worse complications [91]. Peripheral vascular disease was defined as symptoms of claudication, femoral bruit, or absent pedal pulses, and conferred a threefold increase in complication rates ( $31 \%$ vs. $10 \%, p<0.001)$. Female sex was associated with a fourfold increase in complications ( $15 \%$ vs. $4 \%$ ), which is thought to be related to smaller size of the femoral arteries. Similarly, Cohen et al. identified female sex and low BSA $<1.8 \mathrm{~m}$ [2] as higher risk for complication [42]. Another single-center trial of 872 IABP insertions confirmed that vascular complication rates were higher in women (32\% vs. $18 \%$, $p=0.0001$ ) [47], and determined diabetes and hypertension contributed to risk of vascular injury. Risk of infection was only associated with duration of IABP use, and not patientspecific factors. Wasfie et al. demonstrated that diabetic patients have higher overall complication rates when undergoing IABP insertion, specifically if they are insulin dependent (34\% vs. $14 \%$ ) [149]. Most of the increase in complication rate was attributable to minor vascular complications and infection. Smoking history $(p<0.05)$ and peripheral vascular disease as determined by ankle-brachial index (ABI) $(p<0.01)$ have also been identified as significant risk factors for development of limb ischemia [73]. Given the identified risk of vascular complications including limb ischemia in patients with PVD, recent studies have investigated axillary approach for IABP and Impella ${ }^{\circledR}$ given low prevalence of atherosclerosis in this area and the benefit of increased patient mobility with positive outcomes [78, 150]. 
ECMO literature has also cited PVD as a significant risk factor for both early and late vascular complications citing odds ratios of 3.1 and 6.95 $[114,116]$. Contemporary datasets detailing patient- and procedure-specific risk factors are limited, and further work is needed to identify subpopulations of patients who may be at higher risk of complication. Lastly, though not the focus of this topic, prevention of complications remains a crucial aspect in the management of these patients. Using MCS devices for the shortest duration, daily protocols for device weaning, limb assessment, and review of clinical progress is crucial. Furthermore, specific measures as such 'safe femoral practices', use of prophylactic antibiotics, multidisciplinary team management, selection of appropriate anticoagulation targets and LV unloading for ECMO are crucial to achieve optimal outcomes $[2,4,7,8,70,122,151]$.

\section{CONCLUSIONS}

Complications of temporary mechanical circulatory support are associated with worse shortand long-term outcomes [51, 68, 86, 105, 124]. Rates vary widely by study and are affected by timing of the study, single versus multicenter, operator experience, type of MCS, and indication for MCS insertion. Furthermore, true rates of complication are difficult to discern due to variability in reporting and clinical application of each type of support. Additionally, given very few studies have directly compared different types of MCS, comparison of complications and complication rates between devices is challenging.

Trends discussed in this review include highest risk of limb ischemia leading to amputation with IABP insertion, and higher risk of major bleeding with Impella ${ }^{\circledR}$ and TandemHeart ${ }^{\circledR}$, which is balanced by higher overall blood flow rate and improved hemodynamics $[30,39,41,51,65,66,75]$. VA-ECMO has the highest overall complication rate including limb ischemia and CVA, however, it offers the highest level support and often represents the most critically ill patient population $[40,93,105$, 121]. Recent studies have investigated combinations of IABP and Impella ${ }^{\circledR}$ with VA-ECMO as a way to improve overall hemodynamics with significant increase in rates of hemolysis, but without significant increase in incidence of limb ischemia or vascular complications [16, 96, 141, 142, 144-147].

This review is limited by selection of available studies with reported complication rates. Studies selected range in time from 1971 to 2019 , with the majority of literature published after 2010. Indications for mechanical circulatory support were limited to high-risk PCI, acute myocardial infarction, cardiogenic shock, and failure to wean from cardiopulmonary bypass. As mentioned previously, given disparities in study type, time, center, clinical indication for $\mathrm{MCS}$, and operator experience, it is challenging to make direct comparisons across studies or types of MCS.

In summary, complications of MCS are prevalent and vary based on type of device and indication. Due to variability in reporting and study design, true rates of complication and predisposing factors leading to complication are difficult to discern. Review of existing registries including the National Inpatient Sample may be helpful in elucidating these gaps. As such, further work is needed to determine complication rates for specific types and combinations of temporary MCS by clinical application and to identify patient-specific factors that increase risk for complications in this critically ill patient population.

\section{ACKNOWLEDGEMENTS}

Funding. Dr. Saraschandra Vallabhajosyula is supported by the Clinical and Translational Science Award (CTSA) Grant Number UL1 TR000135 from the National Center for Advancing Translational Sciences (NCATS), a component of the National Institutes of Health $(\mathrm{NIH})$. Its contents are solely the responsibility of the authors and do not necessarily represent the official view of NIH. No Rapid Service Fee was received by the journal for the publication of this article. 
Authorship. All named authors meet the International Committee of Medical Journal Editors (ICMJE) criteria for authorship for this article, take responsibility for the integrity of the work as a whole, and have given their approval for this version to be published.

Disclosures. Anna V. Subramaniam, Gregory W. Barsness, Saarwaani Vallabhajosyula, and Saraschandra Vallabhajosyula have nothing to disclose.

Compliance with Ethics Guidelines. This article is based on previously conducted studies and does not contain any studies with human participants or animals performed by any of the authors.

Data Availability. Data sharing is not applicable to this article as no datasets were generated or analyzed during the current study.

Open Access. This article is distributed under the terms of the Creative Commons Attribution-NonCommercial 4.0 International License (http://creativecommons.org/licenses/ by-nc/4.0/), which permits any noncommercial use, distribution, and reproduction in any medium, provided you give appropriate credit to the original author(s) and the source, provide a link to the Creative Commons license, and indicate if changes were made.

\section{REFERENCES}

1. van Diepen S, Katz JN, Albert NM, et al. Contemporary management of cardiogenic shock: a scientific statement from the American Heart Association. Circulation. 2017;136(16):e232-68.

2. Vallabhajosyula S, Barsness GW, Vallabhajosyula S. Multidisciplinary teams for cardiogenic shock. Aging (Albany NY). 2019;11(14):4774-6.

3. Vallabhajosyula S, Dunlay SM, Prasad A, et al. Acute noncardiac organ failure in acute myocardial infarction with cardiogenic shock. J Am Coll Cardiol. 2019;73(14):1781-91.

4. Vallabhajosyula S, Prasad A, Dunlay SM, et al. Utilization of palliative care for cardiogenic shock complicating acute myocardial infarction: a 15-year national perspective on trends, disparities, predictors, and outcomes. J Am Heart Assoc. 2019;8(15):e011954.

5. Vallabhajosyula S, Dunlay SM, Barsness GW, et al. Temporal trends, predictors, and outcomes of acute kidney injury and hemodialysis use in acute myocardial infarction-related cardiogenic shock. PLoS One. 2019;14(9):e0222894.

6. Vallabhajosyula S, Jentzer JC, Kotecha AA, et al. Development and performance of a novel vasopressor-driven mortality prediction model in septic shock. Ann Intensive Care. 2018;8(1):112.

7. Vallabhajosyula S, O'Horo JC, Antharam P, et al. Venoarterial extracorporeal membrane oxygenation with concomitant Impella versus venoarterial extracorporeal membrane oxygenation for cardiogenic shock. Asaio J. 2019.

8. Vallabhajosyula S, O'Horo JC, Antharam P, et al. Concomitant intra-aortic balloon pump use in cardiogenic shock requiring veno-arterial extracorporeal membrane oxygenation. Circ Cardiovasc Interv. 2018;11(9):e006930.

9. Vallabhajosyula S, Arora S, Lahewala S, et al. Temporary mechanical circulatory support for refractory cardiogenic shock before left ventricular assist device surgery. J Am Heart Assoc. 2018;7(22):e010193.

10. Vallabhajosyula S, Arora S, Sakhuja A, et al. Trends, predictors, and outcomes of temporary mechanical circulatory support for postcardiac surgery cardiogenic shock. Am J Cardiol. 2019;123(3):489-97.

11. Vallabhajosyula S, Deshmukh AJ, Kashani K, Prasad A, Sakhuja A. Tako-tsubo cardiomyopathy in severe sepsis: nationwide trends, predictors, and outcomes. J Am Heart Assoc. 2018;7(18):e009160.

12. Vallabhajosyula S, Dunlay SM, Murphree DH Jr, et al. Cardiogenic shock in takotsubo cardiomyopathy versus acute myocardial infarction: an 8-year national perspective on clinical characteristics, management, and outcomes. JACC Heart Fail. 2019;7(6):469-76.

13. Vallabhajosyula S, Kashani K, Dunlay SM, et al. Acute respiratory failure and mechanical ventilation in cardiogenic shock complicating acute myocardial infarction in the USA, 2000-2014. Ann Intensive Care. 2019;9(1):96.

14. Vallabhajosyula S, Prasad A, Gulati R, Barsness GW. Contemporary prevalence, trends, and outcomes of coronary chronic total occlusions in acute myocardial infarction with cardiogenic shock. Int J Cardiol Heart Vasc. 2019;24:100414. 
15. Khorsandi M, Shaikhrezai K, Prasad S, et al. Advanced mechanical circulatory support for postcardiotomy cardiogenic shock: a 20-year outcome analysis in a non-transplant unit. J Cardiothorac Surg. 2016;11:29.

16. Jentzer JC, Vallabhajosyula S, Khanna AK, Chawla LS, Busse LW, Kashani KB. Management of refractory vasodilatory shock. Chest. 2018;154(2):416-26.

17. Kotecha AA, Vallabhajosyula S, Apala DR, Frazee E, Iyer VN. Clinical outcomes of weight-based norepinephrine dosing in underweight and morbidly obese patients: a propensity-matched analysis. J Intensive Care Med. 2018:885066618768180.

18. Poterucha JT, Vallabhajosyula S, Egbe AC, et al. Vasopressor magnitude predicts poor outcome in adults with congenital heart disease after cardiac surgery. Congenit Heart Dis. 2019;14(2):193-200.

19. Rihal CS, Naidu SS, Givertz MM, et al. 2015 SCAI/ ACC/HFSA/STS Clinical Expert Consensus Statement on the Use of Percutaneous Mechanical Circulatory Support Devices in Cardiovascular Care: endorsed by the American Heart Association, the Cardiological Society of India, and Sociedad Latino Americana de Cardiologia Intervencion; Affirmation of Value by the Canadian Association of Interventional Cardiology-Association Canadienne de Cardiologie d'intervention. J Am Coll Cardiol. 2015;65(19):e7-26.

20. Williams DO, Korr KS, Gewirtz H, Most AS. The effect of intraaortic balloon counterpulsation on regional myocardial blood flow and oxygen consumption in the presence of coronary artery stenosis in patients with unstable angina. Circulation. 1982;66(3):593-7.

21. Wernly B, Seelmaier C, Leistner D, et al. Mechanical circulatory support with Impella versus intra-aortic balloon pump or medical treatment in cardiogenic shock-a critical appraisal of current data. Clin Res Cardiol. 2019.

22. Kapur NK, Alkhouli MA, DeMartini TJ, et al. Unloading the left ventricle before reperfusion in patients with anterior ST-segment-elevation myocardial infarction. Circulation. 2019;139(3):337-46.

23. Levy B, Buzon J, Kimmoun A. Inotropes and vasopressors use in cardiogenic shock: when, which and how much? Curr Opin Crit Care. 2019;25(4):384-90.

24. Levy B, Clere-Jehl R, Legras A, et al. Epinephrine versus norepinephrine for cardiogenic shock after acute myocardial infarction. J Am Coll Cardiol. 2018;72(2):173-82.
25. Cheng R, Hachamovitch R, Kittleson M, et al. Complications of extracorporeal membrane oxygenation for treatment of cardiogenic shock and cardiac arrest: a meta-analysis of 1,866 adult patients. Ann Thorac Surg. 2014;97(2):610-6.

26. Sjauw KD, Engstrom AE, Henriques JP. Percutaneous mechanical cardiac assist in myocardial infarction. Where are we now, where are we going? Acute Card Care. 2007;9(4):222-30.

27. Cheng JM, den Uil CA, Hoeks SE, et al. Percutaneous left ventricular assist devices vs. intra-aortic balloon pump counterpulsation for treatment of cardiogenic shock: a meta-analysis of controlled trials. Eur Heart J. 2009;30(17):2102-8.

28. Lee JM, Park J, Kang J, et al. The efficacy and safety of mechanical hemodynamic support in patients undergoing high-risk percutaneous coronary intervention with or without cardiogenic shock: Bayesian approach network meta-analysis of 13 randomized controlled trials. Int $\mathrm{J}$ Cardiol. 2015;184:36-46.

29. O'Neill WW, Kleiman NS, Moses J, et al. A prospective, randomized clinical trial of hemodynamic support with Impella 2.5 versus intra-aortic balloon pump in patients undergoing high-risk percutaneous coronary intervention: the PROTECT II study. Circulation. 2012;126(14):1717-27.

30. Thiele H, Zeymer U, Thelemann N, et al. Intraaortic balloon pump in cardiogenic shock complicating acute myocardial infarction: long-term 6-year outcome of the randomized IABP-SHOCK II trial. Circulation. 2018.

31. Miller PE, Solomon MA, McAreavey D. Advanced percutaneous mechanical circulatory support devices for cardiogenic shock. Crit Care Med. 2017;45(11):1922-9.

32. Kapur NK, Esposito ML, Bader Y, et al. Mechanical circulatory support devices for acute right ventricular failure. Circulation. 2017;136(3):314-26.

33. Ferguson JJ 3rd, Cohen M, Freedman RJ Jr, et al. The current practice of intra-aortic balloon counterpulsation: results from the Benchmark Registry. J Am Coll Cardiol. 2001;38(5):1456-62.

34. Cohen M, Urban P, Christenson JT, et al. Intraaortic balloon counterpulsation in US and non-US centres: results of the Benchmark Registry. Eur Heart J. 2003;24(19):1763-70.

35. Stone GW, Ohman EM, Miller MF, et al. Contemporary utilization and outcomes of intra-aortic balloon counterpulsation in acute myocardial infarction: the Benchmark Registry. J Am Coll Cardiol. 2003;41(11):1940-5. 
36. Hoefer D, Ruttmann E, Poelzl G, et al. Outcome evaluation of the bridge-to-bridge concept in patients with cardiogenic shock. Ann Thorac Surg. 2006;82(1):28-33.

37. Roy SK, Howard EW, Panza JA, Cooper HA. Clinical implications of thrombocytopenia among patients undergoing intra-aortic balloon pump counterpulsation in the coronary care unit. Clin Cardiol. 2010;33(1):30-5.

38. Tempelhof MW, Klein L, Cotts WG, et al. Clinical experience and patient outcomes associated with the TandemHeart percutaneous transseptal assist device among a heterogeneous patient population. ASAIO J. 2011;57(4):254-61.

39. Siriwardena M, Pilbrow A, Frampton C, MacDonald SM, Wilkins GT, Richards AM. Complications of intra-aortic balloon pump use: does the final position of the IABP tip matter? Anaesth Intensive Care. 2015;43(1):66-73.

40. Koerner MM, Harper MD, Gordon CK, et al. Adult cardiac veno-arterial extracorporeal life support (VA-ECMO): prevention and management of acute complications. Ann Cardiothorac Surg. 2019;8(1):66-75.

41. Saura E, Savola J, Gunn J. A 6-year single-center experience of intra-aortic balloon pump treatmentretrospective analysis of 223 patients. J Cardiothorac Vasc Anesth. 2015;29(6):1410-4.

42. Cohen M, Dawson MS, Kopistansky C, McBride R. Sex and other predictors of intra-aortic balloon counterpulsation-related complications: prospective study of 1119 consecutive patients. Am Heart J. 2000;139(2 Pt 1):282-7.

43. Thiele H, Sick P, Boudriot E, et al. Randomized comparison of intra-aortic balloon support with a percutaneous left ventricular assist device in patients with revascularized acute myocardial infarction complicated by cardiogenic shock. Eur Heart J. 2005;26(13):1276-83.

44. Dixon SR, Henriques JP, Mauri L, et al. A prospective feasibility trial investigating the use of the Impella 25 system in patients undergoing high-risk percutaneous coronary intervention (The PROTECT I Trial): initial U.S. experience. JACC Cardiovasc Interv. 2009;2(2):91-6.

45. Kar B, Gregoric ID, Basra SS, Idelchik GM, Loyalka P. The percutaneous ventricular assist device in severe refractory cardiogenic shock. J Am Coll Cardiol. 2011;57(6):688-96.

46. Mueller H, Ayres SM, Conklin EF, et al. The effects of intra-aortic counterpulsation on cardiac performance and metabolism in shock associated with acute myocardial infarction. J Clin Invest. 1971;50(9):1885-900.

47. Kantrowitz A, Wasfie T, Freed PS, Rubenfire M, Wajszczuk W, Schork MA. Intraaortic balloon pumping 1967 through 1982: analysis of complications in 733 patients. Am J Cardiol. 1986;57(11):976-83.

48. Gol MK, Bayazit M, Emir M, Tasdemir O, Bayazit K. Vascular complications related to percutaneous insertion of intraaortic balloon pumps. Ann Thorac Surg. 1994;58(5):1476-80.

49. Kovack PJ, Rasak MA, Bates ER, Ohman EM, Stomel RJ. Thrombolysis plus aortic counterpulsation: improved survival in patients who present to community hospitals with cardiogenic shock. J Am Coll Cardiol. 1997;29(7):1454-8.

50. de Jong MM, Lorusso R, Al Awami F, et al. Vascular complications following intra-aortic balloon pump implantation: an updated review. Perfusion. 2018;33(2):96-104.

51. Thiele H, Jobs A, Ouweneel DM, et al. Percutaneous short-term active mechanical support devices in cardiogenic shock: a systematic review and collaborative meta-analysis of randomized trials. Eur Heart J. 2017;38(47):3523-31.

52. Anderson RD, Ohman EM, Holmes DR Jr, et al. Use of intraaortic balloon counterpulsation in patients presenting with cardiogenic shock: observations from the GUSTO-I Study. Global Utilization of Streptokinase and TPA for Occluded Coronary Arteries. J Am Coll Cardiol. 1997;30(3):708-15.

53. Perera D, Stables R, Thomas M, et al. Elective intraaortic balloon counterpulsation during high-risk percutaneous coronary intervention: a randomized controlled trial. JAMA. 2010;304(8):867-74.

54. Brodie BR, Stuckey TD, Hansen C, Muncy D. Intraaortic balloon counterpulsation before primary percutaneous transluminal coronary angioplasty reduces catheterization laboratory events in highrisk patients with acute myocardial infarction. Am J Cardiol. 1999;84(1):18-23.

55. van 't Hof AW, Liem AL, de Boer MJ, Hoorntje JC, Suryapranata H, Zijlstra F. A randomized comparison of intra-aortic balloon pumping after primary coronary angioplasty in high risk patients with acute myocardial infarction. Eur Heart J. 1999;20(9):659-65.

56. Ohman EM, Nanas J, Stomel RJ, et al. Thrombolysis and counterpulsation to improve survival in myocardial infarction complicated by hypotension and suspected cardiogenic shock or heart failure: 
results of the TACTICS Trial. J Thromb Thrombolysis. $2005 ; 19(1): 33-9$.

57. Valente S, Lazzeri C, Chiostri M, Zucchini M, Giglioli C, Gensini GF. Intra-aortic balloon pump in intensive cardiac care: a registry in Florence. Int J Cardiol. 2011;146(2):238-9.

58. Thiele H, Zeymer U, Neumann FJ, et al. Intraaortic balloon support for myocardial infarction with cardiogenic shock. N Engl J Med. 2012;367(14):1287-96.

59. Davidavicius G, Godino C, Shannon J, et al. Incidence of overall bleeding in patients treated with intra-aortic balloon pump during percutaneous coronary intervention: 12-year Milan experience. JACC Cardiovasc Interv. 2012;5(3):350-7.

60. Zhou M, Yu K, Wang XH, et al. Analysis on application timing of IABP in emergency PCI treatment of patients with combined acute myocardial infarction and cardiac shock. Eur Rev Med Pharmacol Sci. 2017;21(12):2934-9.

61. Seyfarth M, Sibbing D, Bauer I, et al. A randomized clinical trial to evaluate the safety and efficacy of a percutaneous left ventricular assist device versus intra-aortic balloon pumping for treatment of cardiogenic shock caused by myocardial infarction. J Am Coll Cardiol. 2008;52(19):1584-8.

62. Ouweneel DM, Eriksen E, Sjauw KD, et al. Percutaneous mechanical circulatory support versus intraaortic balloon pump in cardiogenic shock after acute myocardial infarction. J Am Coll Cardiol. 2017;69(3):278-87.

63. Ternus BW, Jentzer JC, El Sabbagh A, et al. Percutaneous mechanical circulatory support for cardiac disease: temporal trends in use and complications between 2009 and 2015. J Invasive Cardiol. 2017;29(9):309-13.

64. Karami M, den Uil CA, Ouweneel DM, et al. Mechanical circulatory support in cardiogenic shock from acute myocardial infarction: Impella $\mathrm{CP} / 5.0$ versus ECMO. Eur Heart J Acute Cardiovasc Care. 2019:2048872619865891.

65. Kar B, Adkins LE, Civitello AB, et al. Clinical experience with the TandemHeart percutaneous ventricular assist device. Tex Heart Inst J. 2006;33(2):111-5.

66. Schwartz BG, Ludeman DJ, Mayeda GS, Kloner RA, Economides C, Burstein S. Treating refractory cardiogenic shock with the TandemHeart and Impella devices: a single-center experience. Cardiol Res. 2012;3(2):54-66.
67. Petricevic M, Milicic D, Boban M, et al. Bleeding and thrombotic events in patients undergoing mechanical circulatory support: a review of literature. Thorac Cardiovasc Surg. 2015;63(8):636-46.

68. Xie A, Lo P, Yan TD, Forrest P. Neurologic complications of extracorporeal membrane oxygenation: a review. J Cardiothorac Vasc Anesth. 2017;31(5):1836-46.

69. Lorusso R, Barili F, Mauro MD, et al. In-hospital neurologic complications in adult patients undergoing venoarterial extracorporeal membrane oxygenation: results from the extracorporeal life support organization registry. Crit Care Med. 2016;44(10):e964-72.

70. Sandoval Y, Burke MN, Lobo AS, et al. Contemporary arterial access in the cardiac catheterization laboratory. JACC Cardiovasc Interv. 2017;10(22):2233-41.

71. Vallabhajosyula S, Patlolla SH, Sandhyavenu H, et al. Periprocedural cardiopulmonary bypass or venoarterial extracorporeal membrane oxygenation during transcatheter aortic valve replacement: a systematic review. J Am Heart Assoc. 2018;7(14):e009608.

72. O'Rourke MF, Norris RM, Campbell TJ, Chang VP, Sammel NL. Randomized controlled trial of intraaortic balloon counterpulsation in early myocardial infarction with acute heart failure. Am J Cardiol. 1981;47(4):815-20.

73. Mackenzie DJ, Wagner WH, Kulber DA, et al. Vascular complications of the intra-aortic balloon pump. Am J Surg. 1992;164(5):517-21.

74. Stone GW, Marsalese D, Brodie BR, et al. A prospective, randomized evaluation of prophylactic intraaortic balloon counterpulsation in high risk patients with acute myocardial infarction treated with primary angioplasty. Second Primary Angioplasty in Myocardial Infarction (PAMI-II) Trial Investigators. J Am Coll Cardiol. 1997;29(7):1459-67.

75. Ozen Y, Aksut M, Cekmecelioglu D, et al. Intraaortic balloon pump experience: a single center study comparing with and without sheath insertion. J Cardiovasc Thorac Res. 2018;10(3):144-8.

76. Lemaire A, Anderson MB, Lee LY, et al. The Impella device for acute mechanical circulatory support in patients in cardiogenic shock. Ann Thorac Surg. 2014;97(1):133-8.

77. Kovacic JC, Nguyen HT, Karajgikar R, Sharma SK, Kini AS. The Impella Recover 2.5 and TandemHeart ventricular assist devices are safe and associated with equivalent clinical outcomes in patients 
undergoing high-risk percutaneous coronary intervention. Catheter Cardiovasc Interv. 2013;82(1):E28-37.

78. Kaki A, Blank N, Alraies MC, et al. Axillary artery access for mechanical circulatory support devices in patients with prohibitive peripheral arterial disease presenting with cardiogenic shock. Am J Cardiol. 2019.

79. Meyns B, Dens J, Sergeant P, Herijgers P, Daenen W, Flameng $\mathrm{W}$. Initial experiences with the Impella device in patients with cardiogenic shock-Impella support for cardiogenic shock. Thorac Cardiovasc Surg. 2003;51(6):312-7.

80. Burkhoff D, Cohen H, Brunckhorst C, O’Neill WW. A randomized multicenter clinical study to evaluate the safety and efficacy of the TandemHeart percutaneous ventricular assist device versus conventional therapy with intraaortic balloon pumping for treatment of cardiogenic shock. Am Heart J. 2006;152(3):469.e461-8.

81. Lauten A, Engstrom AE, Jung C, et al. Percutaneous left-ventricular support with the Impella-2.5-assist device in acute cardiogenic shock: results of the Impella-EUROSHOCK-registry. Circ Heart Fail. 2013;6(1):23-30.

82. Ouweneel DM, de Brabander J, Karami M, et al. Real-life use of left ventricular circulatory support with Impella in cardiogenic shock after acute myocardial infarction: 12 years AMC experience. Eur Heart J Acute Cardiovasc Care. 2019;8(4):338-49.

83. Badiye AP, Hernandez GA, Novoa I, Chaparro SV. Incidence of hemolysis in patients with cardiogenic shock treated with Impella percutaneous left ventricular assist device. ASAIO J. 2016;62(1):11-4.

84. Esposito ML, Morine KJ, Annamalai SK, et al. Increased plasma-free hemoglobin levels identify hemolysis in patients with cardiogenic shock and a trans valvular micro-axial flow pump. Artif Organs. 2019;43(2):125-31.

85. Dufour N, Radjou A, Thuong M. Hemolysis and plasma free hemoglobin during extracorporeal membrane oxygenation support: from clinical implications to laboratory details. A review. Asaio J. 2019.

86. Zangrillo A, Landoni G, Biondi-Zoccai G, et al. A meta-analysis of complications and mortality of extracorporeal membrane oxygenation. Crit Care Resusc. 2013;15(3):172-8.

87. Murphy DA, Hockings LE, Andrews RK, et al. Extracorporeal membrane oxygenation-hemostatic complications. Transfus Med Rev. 2015;29(2):90-101.

88. Alli OO, Singh IM, Holmes DR Jr, Pulido JN, Park SJ, Rihal CS. Percutaneous left ventricular assist device with TandemHeart for high-risk percutaneous coronary intervention: the Mayo Clinic experience. Catheter Cardiovasc Interv. 2012;80(5):728-34.

89. Sokolovic M, Pratt AK, Vukicevic V, Sarumi M, Johnson LS, Shah NS. Platelet count trends and prevalence of heparin-induced thrombocytopenia in a cohort of extracorporeal membrane oxygenator patients. Crit Care Med. 2016;44(11):e1031-7.

90. Natt B, Hypes C, Basken R, Malo J, Kazui T, Mosier J. Suspected heparin-induced thrombocytopenia in patients receiving extracorporeal membrane oxygenation. J Extra Corpor Technol. 2017;49(1):54-8.

91. Gottlieb SO, Brinker JA, Borkon AM, et al. Identification of patients at high risk for complications of intraaortic balloon counterpulsation: a multivariate risk factor analysis. Am J Cardiol. 1984;53(8):1135-9.

92. Brechot N, Luyt CE, Schmidt M, et al. Venoarterial extracorporeal membrane oxygenation support for refractory cardiovascular dysfunction during severe bacterial septic shock. Crit Care Med. 2013;41(7):1616-26.

93. Wang L, Wang H, Hou X. Clinical outcomes of adult patients who receive extracorporeal membrane oxygenation for postcardiotomy cardiogenic shock: a systematic review and meta-analysis. J Cardiothorac Vasc Anesth. 2018;32(5):2087-93.

94. Garan AR, Takeda K, Salna M, et al. Prospective comparison of a percutaneous ventricular assist device and venoarterial extracorporeal membrane oxygenation for patients with cardiogenic shock following acute myocardial infarction. J Am Heart Assoc. 2019;8(9):e012171.

95. Papadopoulos N, Marinos S, El-Sayed Ahmad A, et al. Risk factors associated with adverse outcome following extracorporeal life support: analysis from 360 consecutive patients. Perfusion. 2015;30(4):284-90.

96. Rastan AJ, Dege A, Mohr M, et al. Early and late outcomes of 517 consecutive adult patients treated with extracorporeal membrane oxygenation for refractory postcardiotomy cardiogenic shock. J Thorac Cardiovasc Surg. 2010;139(2):302-11.

97. Kolla S, Lee WA, Hirschl RB, Bartlett RH. Extracorporeal life support for cardiovascular support in adults. ASAIO J. 1996;42(5):M809-19. 
98. Raiten JM, Wong ZZ, Spelde A, Littlejohn JE, Augoustides JGT, Gutsche JT. Anticoagulation and transfusion therapy in patients requiring extracorporeal membrane oxygenation. J Cardiothorac Vasc Anesth. 2017;31(3):1051-9.

99. Moulopoulos S, Stamatelopoulos S, Petrou P. Intraaortic balloon assistance in intractable cardiogenic shock. Eur Heart J. 1986;7(5):396-403.

100. Funk M, Gleason J, Foell D. Lower limb ischemia related to use of the intraaortic balloon pump. Heart Lung. 1989;18(6):542-52.

101. Friedell ML, Alpert J, Parsonnet V, et al. Femorofemoral grafts for lower limb ischemia caused by intra-aortic balloon pump. J Vasc Surg. 1987;5(1):180-6.

102. Alderman JD, Gabliani GI, McCabe $\mathrm{CH}$, et al. Incidence and management of limb ischemia with percutaneous wire-guided intraaortic balloon catheters. J Am Coll Cardiol. 1987;9(3):524-30.

103. Thiele H, Zeymer U, Neumann FJ, et al. Intra-aortic balloon counterpulsation in acute myocardial infarction complicated by cardiogenic shock (IABPSHOCK II): final 12 month results of a randomised, open-label trial. Lancet. 2013;382(9905):1638-45.

104. Gulkarov I, Bobka T, Elmously A, et al. The effect of acute limb ischemia on mortality in patients undergoing femoral veno-arterial extracorporeal membrane oxygenation. Ann Vasc Surg. 2019.

105. Yau P, Xia Y, Shariff S, et al. Factors associated with ipsilateral limb ischemia in patients undergoing femoral cannulation extracorporeal membrane oxygenation. Ann Vasc Surg. 2019;54:60-5.

106. Avalli L, Sangalli F, Migliari M, et al. Early vascular complications after percutaneous cannulation for extracorporeal membrane oxygenation for cardiac assist. Minerva Anestesiol. 2016;82(1):36-43.

107. Wong JK, Melvin AL, Joshi DJ, et al. Cannulationrelated complications on veno-arterial extracorporeal membrane oxygenation: prevalence and effect on mortality. Artif Organs. 2017;41(9):827-34.

108. Ranney DN, Benrashid E, Meza JM, et al. Vascular complications and use of a distal perfusion cannula in femorally cannulated patients on extracorporeal membrane oxygenation. ASAIO J. 2018;64(3):328-33.

109. Collier PE, Liebler GA, Park SB, Burkholder JA, Maher TD, Magovern GJ. Is percutaneous insertion of the intra-aortic balloon pump through the femoral artery the safest technique? J Vasc Surg. 1986;3(4):629-34.
110. Goldberger M, Tabak SW, Shah PK. Clinical experience with intra-aortic balloon counterpulsation in 112 consecutive patients. Am Heart J. 1986;111(3):497-502.

111. Goldberg MJ, Rubenfire M, Kantrowitz A, et al. Intraaortic balloon pump insertion: a randomized study comparing percutaneous and surgical techniques. J Am Coll Cardiol. 1987;9(3):515-23.

112. Juo YY, Skancke M, Sanaiha Y, Mantha A, Jimenez JC, Benharash P. Efficacy of distal perfusion cannulae in preventing limb ischemia during extracorporeal membrane oxygenation: a systematic review and meta-analysis. Artif Organs. 2017;41(11):E263-73.

113. Bonicolini E, Martucci G, Simons J, et al. Limb ischemia in peripheral veno-arterial extracorporeal membrane oxygenation: a narrative review of incidence, prevention, monitoring, and treatment. Crit Care. 2019;23(1):266.

114. Zimpfer D, Heinisch B, Czerny $M$, et al. Late vascular complications after extracorporeal membrane oxygenation support. The Annals of Thoracic Surgery. 2006;81(3):892-5.

115. Foley PJ, Morris RJ, Woo EY, et al. Limb ischemia during femoral cannulation for cardiopulmonary support. J Vasc Surg. 2010;52(4):850-3.

116. Bisdas T, Beutel G, Warnecke G, et al. Vascular complications in patients undergoing femoral cannulation for extracorporeal membrane oxygenation support. Ann Thor Surg. 2011;92(2):626-31.

117. Lamb KM, DiMuzio PJ, Johnson A, et al. Arterial protocol including prophylactic distal perfusion catheter decreases limb ischemia complications in patients undergoing extracorporeal membrane oxygenation. J Vasc Surg. 2017;65(4):1074-9.

118. Harris M, Karamasis GV, Chotai S, Tang KH, Clesham GJ, Kelly PA. Spinal cord infarction post cardiac arrest in STEMI: a potential complication of intra-aortic balloon pump use. Acute Card Care. 2016;18(1):18-21.

119. Ohman EM, George BS, White CJ, et al. Use of aortic counterpulsation to improve sustained coronary artery patency during acute myocardial infarction. Results of a randomized trial. The Randomized IABP Study Group. Circulation. 1994;90(2):792-9.

120. Ohman EM, Califf RM, George BS, et al. The use of intraaortic balloon pumping as an adjunct to reperfusion therapy in acute myocardial infarction. The Thrombolysis and Angioplasty in Myocardial Infarction (TAMI) Study Group. Am Heart J. 1991;121(3 Pt 1):895-901. 
121. Allou N, Lo Pinto H, Persichini R, et al. Cannularelated infection in patients supported by peripheral ECMO: clinical and microbiological characteristics. ASAIO J. 2019;65(2):180-6.

122. O'Horo JC, Cawcutt KA, De Moraes AG, Sampathkumar P, Schears GJ. The evidence base for prophylactic antibiotics in patients receiving extracorporeal membrane oxygenation. ASAIO J. 2016;62(1):6-10.

123. Organization ELS. ELSO Guidelines for Cardiopulmonary Extracorporeal Life Support. 2017; Version 1.4:https://www.elso.org/Portals/0/ELSO\% 20Guidelines\%20General\%20All\%20ECLS\% 20Version\%201_4.pdf. Accessed 3 Sep 2019.

124. Kotecha A, Vallabhajosyula S, Coville HH, Kashani $\mathrm{K}$. Cardiorenal syndrome in sepsis: a narrative review. J Crit Care. 2018;43:122-7.

125. Vallabhajosyula S, Geske JB, Kumar M, Kashyap R, Kashani K, Jentzer JC. Doppler-defined pulmonary hypertension in sepsis and septic shock. J Crit Care. 2019;50:201-6.

126. Vallabhajosyula S, Jentzer JC, Geske JB, et al. Newonset heart failure and mortality in hospital survivors of sepsis-related left ventricular dysfunction. Shock. 2018;49(2):144-9.

127. Vallabhajosyula S, Kumar M, Pandompatam G, et al. Prognostic impact of isolated right ventricular dysfunction in sepsis and septic shock: an 8-year historical cohort study. Ann Intensive Care. 2017;7(1):94.

128. Vallabhajosyula S, Pruthi S, Shah S, Wiley BM, Mankad SV, Jentzer JC. Basic and advanced echocardiographic evaluation of myocardial dysfunction in sepsis and septic shock. Anaesth Intensive Care. 2018;46(1):13-24.

129. Vallabhajosyula S, Rayes HA, Sakhuja A, Murad MH, Geske JB, Jentzer JC. Global longitudinal strain using speckle-tracking echocardiography as a mortality predictor in sepsis: a systematic review. J Intensive Care Med. 2019;34(2):87-93.

130. Vallabhajosyula S, Sakhuja A, Geske JB, et al. Clinical profile and outcomes of acute cardiorenal syndrome type-5 in sepsis: an eight-year cohort study. PLoS One. 2018;13(1):e0190965.

131. Vallabhajosyula S, Sakhuja A, Geske JB, et al. Role of admission troponin- $T$ and serial troponin- $T$ testing in predicting outcomes in severe sepsis and septic shock. J Am Heart Assoc. 2017;6(9):e005930.

132. Pandompatam G, Kashani K, Vallabhajosyula S. The role of natriuretic peptides in the management, outcomes and prognosis of sepsis and septic shock. Rev Bras Ter Intensiva. 2019;31(3):368-78.

133. Falk L, Hultman J, Broman LM. Extracorporeal membrane oxygenation for septic shock. Crit Care Med. 2019;47(8):1097-105.

134. Vogel DJ, Murray J, Czapran AZ, et al. Veno-arteriovenous ECMO for septic cardiomyopathy: a singlecentre experience. Perfusion. 2018;33(1_suppl):57-64.

135. Combes A, Hajage D, Capellier G, et al. Extracorporeal membrane oxygenation for severe acute respiratory distress syndrome. $\mathrm{N}$ Engl $\mathrm{J}$ Med. 2018;378(21):1965-75.

136. Chandra NGS, Vallabhajosyula S, Shastry BA, Vallabhajosyula S, Vallabhajosyula S, Saravu K. Use of corticosteroids in acute respiratory distress syndrome: perspective from an Indian intensive care unit. Med J Armed Forces India. 2017;73(2):118-22.

137. Vallabhajosyula S, Trivedi V, Gajic O. Ventilation in acute respiratory distress syndrome: importance of low-tidal volume. Ann Transl Med. 2016;4(24):496.

138. Russo JJ, Aleksova N, Pitcher I, et al. Left ventricular unloading during extracorporeal membrane oxygenation in patients with cardiogenic shock. J Am Coll Cardiol. 2019;73(6):654-62.

139. Truby LK, Takeda K, Mauro C, et al. Incidence and implications of left ventricular distention during venoarterial extracorporeal membrane oxygenation support. ASAIO J. 2017;63(3):257-65.

140. Aso S, Matsui H, Fushimi K, Yasunaga H. The effect of intraaortic balloon pumping under venoarterial extracorporeal membrane oxygenation on mortality of cardiogenic patients: an analysis using a nationwide inpatient database. Crit Care Med. 2016;44(11):1974-9.

141. Pappalardo F, Schulte C, Pieri M, et al. Concomitant implantation of Impella((R)) on top of veno-arterial extracorporeal membrane oxygenation may improve survival of patients with cardiogenic shock. Eur J Heart Fail. 2017;19(3):404-12.

142. Mourad M, Gaudard P, De La Arena P, et al. Circulatory support with extracorporeal membrane oxygenation and/or Impella for cardiogenic shock during myocardial infarction. ASAIO J. 2018;64(6):708-14.

143. Patel SM, Lipinski J, Al-Kindi SG, et al. Simultaneous venoarterial extracorporeal membrane oxygenation and percutaneous left ventricular decompression therapy with Impella is associated with improved outcomes in refractory cardiogenic shock. ASAIO J. 2019;65(1):21-8. 
144. Park TK, Yang JH, Choi SH, et al. Clinical impact of intra-aortic balloon pump during extracorporeal life support in patients with acute myocardial infarction complicated by cardiogenic shock. BMC Anesthesiol. 2014;14:27.

145. Tepper S, Masood MF, Baltazar Garcia M, et al. Left ventricular unloading by Impella device versus surgical vent during extracorporeal life support. Ann Thorac Surg. 2017;104(3):861-7.

146. Akanni OJ, Takeda K, Truby LK, et al. EC-VAD: combined use of extracorporeal membrane oxygenation and percutaneous microaxial pump left ventricular assist device. ASAIO J. 2019;65(3):219-26.

147. Schrage B, Burkhoff D, Rubsamen N, et al. Unloading of the left ventricle during venoarterial extracorporeal membrane oxygenation therapy in cardiogenic shock. JACC Heart Fail. 2018;6(12):1035-43.
148. Meani P, Gelsomino S, Natour E, et al. Modalities and effects of left ventricle unloading on extracorporeal life support: a review of the current literature. Eur J Heart Fail. 2017;19(Suppl 2):84-91.

149. Wasfie T, Freed PS, Rubenfire M, et al. Risks associated with intraaortic balloon pumping in patients with and without diabetes mellitus. Am J Cardiol. 1988;61(8):558-62.

150. Moussa Pacha H, Al-Khadra Y, Alraies MC. Transaxillary intra-aortic balloon pump placement: a new approach with great potential. Mayo Clin Proc. 2018;93(4):539-40.

151. Aubron C, McQuilten Z, Bailey M, et al. Low-dose versus therapeutic anticoagulation in patients on extracorporeal membrane oxygenation: a pilot randomized trial. Crit Care Med. 2019;47(7):e563-71. 